\title{
Bit and Bit Product Thinking
}

\author{
Junwei Chen ${ }^{1,2}$, Yangbo Zhang ${ }^{1,2}$, Xiao Kang ${ }^{1}$ and Huaying Shu ${ }^{1,2}$ \\ ${ }^{1}$ School of Economics and Management, Beijing University of Posts and Telecommunications, Beijing 100876, China \\ ${ }^{2}$ Service Management Science Research Institute, Beijing University of Posts and Telecommunications, Beijing 100876, China \\ chenjunwei@bupt.edu.cn,buzhangyangbo@163.com,422314446@qq.com, shuhy@bupt.edu.cn
}

\begin{abstract}
Over the past two decades, the popularity of the ICT has brought humans into an unprecedented era of information. A academia go into in-depth study of related fields, and has made great progress in the fields of information economy, knowledge-based economy, the network economy, and virtual economy. However, none can provide a unified and comprehensive explanation about the new economic phenomena such as a wide range of free internet applications in our daily life. The bit economy research has emerged to heap up with the times. This article, based on the bit economy, firstly discusses bit and its existing cyberspace from the aspect of natural philosophy, and redefine cyberspace and bit from the point of view of the origin of the world. Then we contrast bit product with atom product to discuss in-depth on how to understand bit product, and define it based on the difference of the connotation from digital products. At last, we explain the key point to cognize bit product from the three aspects of existence, connotation, and appreciable characters.

Index Terms - Bit; Information; Cyberspace; Bit Product.
\end{abstract}

\section{Bit Origins}

Your goal is to simulate the usual appearance of papers in IEEE conference proceedings. For items not addressed in these instructions, please refer to the last issue of your conference's proceedings for reference or ask your conference Publications Chair for instructions.

\section{A. The Traditional and the New Labor Object - Information}

Since humans could use the tools, there has been a notion of productive labor and respectively, the cognition of subject of labor and means of labor, including production tools, land, roads, etc. About one hundred and fifty years ago, in his book Das Kapital, Marx thoroughly described and highly summarized the subject of labor and means of labor, the subject of labor was defined as 'all things that people devoted their own labor into, also the object of labor'. And he pointed out that this object includes both naturally existing things and things produced through labor processing.

Before the information age, the main object of labor, such as minerals, agricultural products, clothing textiles and other kinds of objects existed as the form of material, which are tangible in the real material world. From the standpoint of physics the subject of labor can be explained as the collection of elementary particles which is composed of limited types of elementary particles in different numbers and different combinations. It can be measured with a variety of physical means and fully perceived through a variety of sensory organs.

After entering the information age, both traditional and new information on the labor in production and living gradually caught everyone's attention. As a kind of means of labor, in fact, information not only already exists, but also has played a very important role in the development of human civilization. However, information has not attracted the same attention as the other subject of labor with its acute shortage of research and theory. The reason for this difference is the completely unpredictable nature of information in the physical world, and people learn indirectly through books, etc., so that it is difficult to have a thorough understanding for a long period of time.

Scholars began to study information and its economic phenomenon since the beginning of the twentieth century, one after another, but it was not until the late fifties that began to show the outbreak of large growth, including Shannon, Wiener, Hartley, Zhong Yixin, the large number of scholars who have carried out in-depth research and defined information. Because of the involvement of the contents philosophy and level of abstraction, such as bit world, cyberspace and the spiritual world, therefore, there is more agreement on Professor Zhong Yixin's definition of comprehensive information [1]: The information includes two levels, ontology and epistemology. Ontology explains information as self-expression of the state of movement and change of things; on the other hand, the epistemological view is that information is perceived by the subject (or expressed) on the state of movement and change of things, including such state or mode of form, meaning and effect. What requires special attention is that information is neither material (here refers to a narrowly defined material, different from Lenin's reference to an objective definition of generalized material objects) nor energy (also a kind of a generalized material), the information is the information.

From the definition, we can easily understand that from the point of ontology, information is defined to be an objective reality, an expression of source (i.e. anything), which does not change with the existence of sink or the reception of sink, and cognition of materialism. Nevertheless, in the definition of epistemology, the existing form and expressional meaning of information depends on the ability of feeling, understanding, and judgment. Once out of sink, it would be gone, which is more biased in favor of idealism.

\section{B. The Rise of Bit}

After in-depth research on 'information', the traditional and new subject of labor, scholars continue to do thorough research on knowledge derived from information, and the phenomenon of information economy, knowledge economy, network economy, and virtual economy, as well as the 
corresponding products of information, knowledge, network, and the digital, creating information economics, knowledge economics, network economics, and virtual economics, which are interrelated but also diverse research areas. As a result, research regarding information, the special type of object of labor, is greatly enriched, which constitutes the foundation of a new economic study of the information age.

Since late 19th century and early 20th century, with the rise of electronic technology, more and more electronic products pour into people's daily life; at the same time, people are increasingly dependent on these electronic products. These products not only provide convenience to people's daily life, but also allow people to gradually realize a new virtual world wholly composed of various instructions and codes. The invention and the popularity in particular, of computers and internet offers thousands of families a glimpse into this novel world through the unique window, pulling the so-called 'virtual world' to one and another high point in the status of people's lives. In the academic field, research regarding this virtual world is also carried out progressively and enriched.

It is the bit that constitutes the basis of 'virtual word' rather than a variety of elementary particles, which is also the object of this research study.

Bit is was first used by scholar John Wilder Turkey in the 1940 s, as a term in the early computer research process, which is taken from the former part of the 'binary' and latter part of 'digit' [2]. In 1948 American scholar Claude Elwood Shannon in his paper A Mathematical Theory of Communication introduced the word of bit, and described it as 'a unit of measurement of the amount of information that can be stored in equipment that contains two stable states [3]. Because of Shannon's transcendent status in the field of information theory research, the descriptive definition of bit has become a commonly used term also in the field of information science.

Based on Shannon's definition of bit, this study regards bit as an object rather than a unit of measurement, of which the main purpose is emphasize the specialty of the research object relative to the general concept of information, that is, bit is a kind of information, a subset of the information, and its existence and propagation must depends on the 'a device' containing two stable states (at present, that is, various electronic devices such as computer ). Therefore, on current technological conditions, bit is a kind of special information that must rely on electronic device. We also note that bit exists in the so-called 'virtual world' (which will discuss later in depth), but the corresponding bit economy and virtual economy is not in the same kind. Virtual economy still doesn't have a definition and connotation which a majority of scholars agree with. However, they generally agreed that it can be traced back to the issue of paper money, that is, to the economic activity where value of symbol and its derivative products such as bank notes, shares, securities, electronic money, etc., are the basic transaction object Popular to say, it is an economy not for trading in kind [2]. This economy does not depend on specific implementation platform but has specific requirements on the transaction object (or subject matter). Bit economy, taken the characteristic of bits into consideration, must be achieved on an electronic device. So in essence, bit economy and is completely different from virtual economy.

\section{The Bit World}

\section{A. About the World}

In the field of natural philosophy, there are a large number of studies on the origin, characteristics and types of the world among which the most typical view is by Austrian-born Jewish British philosopher, Karl Raimund Popper. In the 1970s, he proposed that the human world could be divided into three parts according to the different properties of the objectoriented: World 1 is the physical world, including physical entities and physical state, the material world where we now exist; World 2 is the world of mental or psychological, which exists depending on human thought; World 3 is the world of the products of human mind, that is, the objective knowledge world [4]. It is a world of ideological content, objective knowledge and is not associated with people themselves, but made up of logical relations and objective knowledge. This view is advanced because it divides human cognitive world into three levels with clear boundaries between each level and strong identifiably. At present, theorists have few controversies about Popper's theory [5], but with the development of human cognition and science and technology, Popper's three world theory has been increasingly unable to meet the needs of the academic-related research in the corresponding field, so scholars, put forward the theory of world 4 and world framework, on the basis of the three world theory.

In the academic field, there are four categories of discussion about world 4 . The first category holds the view that human society has generated a so-called 'world of symbols' (the world 4) [6]; the second believes that world 4 is a 'virtual world' or 'digital world' [7][8]; the third category supports that world 4 exists, but belongs to a 'technological world' or 'cultural world' [9]; the last category points out that world 4 simply does not exist, and the so-called world 4 is just a natural extension of world 3 and another expression that does not have its own unique attributes.

From the data accumulated by the Institute as well as we own awareness, the second type of understanding is favorable, that is world 4 has been formed, which is different from Popper's three world, and it is a 'virtual world'. In the first kind of cognition, representation of 'world of symbols' is easily misunderstood and confused with 'symbolic', which has been widely studied [5]. In the third category, the 'cultural world' or 'technological world' can be mapped to the three worlds of Popper's theory respectively, which is only a kind of morphology of the three worlds. There is no essential difference.

However, in the second kind of cognition, the 'virtual world', of which there is no widely accepted definition, is quite vague in terms of reference. In a narrow sense, the virtual world is combined with the technology of AI, CG, HMI, 
Sensor, and P\&R Computing by providing an interactive artificial reality. It is a man-machine interface with highly realistic simulation of human's behavior and perception in the real world, that is, the virtual reality consists of existing online communities, online family, and online games. The generalized virtual world is a new action space for the exchange of information, knowledge, ideas and emotions of human with the development of computer network technology and human network operations presented, is a non-entity existence and process. From these points of view, the 'virtual world' is not a very accurate description of the object of this study - bit world (or space, the same below), so it is necessary to do further clarification.

\section{B. Cyberspace}

In 1982, Canadian novelist William Gibson in Omni magazine published short stories - Burning Chrome combined cybernetics and space to create and use a new word cyberspace, which was known for the success of the 1984 novel Neuromancer.

In recent years, with the development of the Internet and getting closer and closer to people's daily lives, cyberspace attracts more and more attention by scholars, and even the U.S. government and military has released nearly a hundred Cyberspace strategy and guidance documents, and establishes the U.S. Cyber Command, highlighting the importance of cyberspace. The U.S. National Security Presidential Directive 54/Homeland Security Presidential Directive 23 (NSPD54/HSPD23) defines cyberspace as the interdependent network of information technology infrastructures, and includes the Internet, telecommunications networks, computer systems, and embedded processors and controllers in critical industries. Common usage of the term also refers to the virtual environment of information and interactions between people [10]. Judging from this definition, cyberspace has also been translated into the network space, but it contains space is not limited to network, also includes a separate computer system (In a sense, this is a unique network). This particularity in cyberspace has become clearer from the U.S. Department of Defense Dictionary of Military and Associated Terms. In the Dictionary, Cyberspace is defined as a global domain within the information environment [11], which illustrates the scope and object of Cyberspace intuitively. We believes that, although the White House and the Department of Defense defines cyberspace or with political purposes more or less, the United States, as the vanguard of research and a master, the definition from its political center is still fairly representative. In addition, explaining the environment in which the bit exists, this definition can not only be distinguished from the virtual world of the traditional cognitive, but also be able to avoid the vagueness of the definitions and boundaries of the virtual space under the framework of the World 4, and even has laid a good foundation for the follow-up study. In this study, according to the previous definition, cyberspace is defined as: existing in IT infrastructure or equipment, the world mapped by the world 1, 2, 3 and the world different from the world mapped by the world 1, 2, 3, generating from these infrastructure.(i.e. before mentioned the so-called world 4). This study also believes that bit exists and exists only in cyberspace, and is the only subject of labor in cyberspace. All products in the cyberspace are produced by using material means of labor such as computers and virtual means of labor such as knowledge, adding various forms of labor to the bit.

\section{Bit Product}

\section{A. Bit and Atom}

The important element constituting the traditional material world is atom, but the cornerstone of cyberspace is bit. It is presented on a continuous series of binary digits 0 and 1 in the mapping transformation from the Cyberspace to the physical world.

Because of the difference between the operating rules of Bits and Atoms, cyberspace and reality of the material world were created precisely important differences: the atoms are specific, indeed, visible, tangible, while the bits have no size, weight, color, shape, but be able to break through the constraints of space-time and even spread at breakneck speed; the atoms can be easily consumed only for a limited number of uses, and its value is gradually decreasing with the increase in the number of use, but the bits can easily copy and wear resistance available for unlimited use, and because of the presence of network externalities, their value increase with the number of users gradually increasing.

With the fast change and development of modern information technology, the world has changed from the one consisted by atoms to the one consisted by bits and atoms binary basis. Bit as 'the DNA of information' [12] is rapidly growing, and it has already become basic elements of human society along with the atom. As Nicholas Negro Ponte said 'Move bits, not atoms', the world composed of atoms has changed into the world that bits and atoms coexist. With deepening importance of bit in daily life, the products that bits as the components are increasingly rich and flourished. These products not only occupy one's sporadic time, but also have generally been used in the communications industry, medical industry, education industry, the publishing industry, and other aspects of life.

\section{B. Bit Product and Digital Products}

From the moment that a number of experts and scholars were aware that the information revolution worldwide made the world we live in extended to the cyberspace, controversies over the description of the product in this space has never stopped. The names such as information products, knowledge products, network products and digital products are constantly studied and used by many experts and scholars. We believes that we should understand these products at the spirit of 'seeking common ground while reserving differences': the same refers to their common intersection, where the same is that these products contain information content; differences refers to the difference between them. The key point to distinguish them is that the core factor of these products is significantly different. 
Just as the name implies, the core factor (or primary requirements) of information products, knowledge products and network products respectively are 'containing information', 'knowledge content' and 'relying on network conditions', which are relatively easy to distinguish, and academia has more unified cognition. However, there is not very unified definition and understanding for digital products and digitized products closely related products with 'bits', so that some related definitions are fuzzy and confusing. Consequently, in this article, academic research were aggregated and summarized to clarify the significance of the concept of 'bit product'.

Summarizing the relevant literature, we find that the definition of digital products has three following perspectives:

1) The concept of digital products should be understood from both broad sense and narrow sense, which includes tangible digital products and intangible digital products.

Digital products in a narrow sense refer to the information content of the exchange of objects based on digital format, or the delivery of products is via the Internet in the way of bit. These are intangible digital products. The generalized digital products in addition to the narrow digital products include electronic products based on digital technology or the product that be presented in the certain of the physical carrier and can be converted to digital form, propagate, receive and dispatch through the network. These are tangible digital products [13].

This definition for digital products includes the broadest areas of digital products; there are many scholars who hold this view. It should be noted particularly that three categories of products are included in this definition: 'The first category of products' is the content based on the digital format or the bit stream, and can be transported via the Internet, i.e., the intangible digital products in the above concepts; 'The second category of products' is the products that can be digitized and be able to transfer through the transmission network such as the Internet, whether or not it has been digitized. Such product contain their material carrier is the tangible digital products. Such as the disk or CD forms of the software, movies, etc. also belong to this category of digital products; 'The third category of products' is the electronic product based on digital technology, where the product is a combination of hardware and software.

2) Digital products are tangible products, which are the product of the combination of internal digitizing invisible software and external materialistic visible hardware. The internal and external, software and hardware, visible and the invisible together are indispensable.

Scholars hold this view believe that the product is a digital electronic media, is an intermediate, whose main task is to provide and transit information, is a medium of information exchange, the combination of software and hardware interface, the carrier of service and experience, is a tangible product that is the aforementioned 'the third category of products'.

For example, Yi Li (2005) argues that digital product exist to a certain extent mainly because of the presence of the digitized information, and all the products based on the digital technology can be called digital products[14]. Research on digital products in the paper is mainly for the "3C products", which is the term of computer, communication and consumer electronics, three categories of products. Yao Xingen (2004) thinks that digital products are digital technology, network technology which continues to develop, and providing traditional services and instant landing Internet services through the digital way, which also are low-cost, portable, reliable, easy to use products for customers[15].

There are also some papers on digital product design and user experience delineate the digital products for tangible products using digital technology, which is too numerous to list here.

3) Digital products are intangible products that can be digitized (converted into binary digital format) for all products or services [16].

This type of digital products can be seen as the product or service that can be digitally encoded into some bytes and be transported through a digital network such as the Internet, that is what we have said 'the first category of products' [17][18].

C. Shapiro and H. Varian (2000) point out that digital products contain digital format exchange in their book Information Rules: A Strategic Guide to the Network Economy.[19] The United Nations Conference on Trade and Development (UNCTAD) defines digital products in its publication of a meeting report from the starting point of transfer, it shows that digital products can either transport by the physically transport carrier, or be delivered electronically via the Internet products. Rui Tingxian (2002) considers that all things that send and receive on the Internet can become digital products, as well as the no corresponding kind of product or service which exist in the form of knowledge or process.[18]

In addition to these three main points, some scholars also believe that the digital products is included with the 'the first category' and 'the second category' mentioned in this article. In her definition, the 'the first category' is narrow digital products while the 'the second category' is the generalized digital products. The scholars give different definitions to digital products, but it can be seen that the digital products include the three types of products as was said earlier. We can regard it as one of the aforementioned three categories of products or a combination of them.

Academia also disputed not only the definition of digital products, but also the understanding of the relationship between digital products and digitized products today. The first view is that the digitized products are equivalent to the concept of digital products, which can be referred to as digitized product, such as Yuan Hong (2007) [20]. The second view is that digitized products include digital products. Xie Kang (2003) believes that digital products must be digitized products, and digital products are the intersection of digitized products and information products [21]. Rui Tingxian(2002) views that digitized products may be digital products, but they also may not be digital products, such as software and CD are both digital products and also digitized products, while the 
digitized weapons or digitized household electrical appliances are digitized products, but not digital products[18]. The third view is that the two are the relationship of process and results, rather than containing and being contained relations. Such as Zhou Changqing (2010) believes that digital products are intangible information products produced by computer processing and existing in digital form, while the digitized product are the use of computer technology to the product transformation to digital form of the production process, that means digitized products are the results of digital products[22].

There is no doubt that it is the development of the digital technology that prompted the products exists in digital format and bit stream gradually increased. The essence of the digital products is the information content of the digital format, i.e. digital products addition themself have usefulness of the information, it is also emphasized the information in digital format. This shows that, the information content in the digital format is the core factor of production for the digital products. The existence form of digital or digital encoding format is the foremost characteristic of the digital products.

However, it can be seen that from the above summary of the literature, it is the objective reality that there is no uniform understanding of the digital products. In most cases, the tangible digital products which is the material and cultural symbols of the digital world showing invisible digital information is classified to the scope of digital products. Thus, the use of the name 'digital products' can not directly express the most essential features of cyberspace we live in- bits state exists, which will result in some confusion and distress of academic exploration. Based on this, proposing the concept of 'bit product' create a new era when further research can be done about bits, as the sole subject of labor that exists in cyberspace.

\section{Definition of Bit Product}

In The Bit Economy, the writer gives a much more clear and comprehensive narrative to the definition of the bit product. The bit product has its broad sense and narrow sense. In a narrow sense, the bit product is defined as information products existing in the form of bit or bit streams. While in a broad sense, the bit product includes not only the narrow bit product, but also the bit service in bits or bit streams [2].

The father of modern marketing, Philip Kotler, defines 'product' as anything that be able to provide to meet the needs and desires of the market in his book Marketing Management. In 2002, the Manual on Statistics of International Trade in Services states that 'Service is not an entity that is able to determine the independent ownership. They can not be transacted without production. Service is heterogeneous output of the customizing production, is activity in which producer engages according to consumption need to achieve the status of the consumer unit changes. When completed, it must have been available to consumers. [21]' With the development and progress of society, more and more phenomenon of product servitization comes up. The cyberspace we live in not only includes a separate computer systems (also a kind of network but rather small), but also contains vast borderless network space. It is precisely because of the complexity of computer network makes bit product and service much more convergent.

Relying on information technology, when consumer acceptance online services in cyberspace, the Internet makes products convert to service, which means that under normal circumstances products provided by the Internet can be seen as bit service. In addition, in some cases, bit product and service are inseparable. For example, when we watch a video on the Internet, the web site offers video management, indexing, and distribution behavior etc., which can be regard as bit service, however, the video itself is a kind of content bit product. We can regard watching a video as a bit service or a bit product we enjoy. Email, a bit product that users can edit it by themselves, must be accompanied by the bit service provided by 163, 126, Yahoo, Gmail and other enterprises. When we use the APP store, service and applications has come into the store in a predictable manner. The experience process of the customer searching application is both the process of using bit product and accepting bit service.

In this paper, based on the perception of this phenomenon, we define the bit product by using its key point, after limiting and integrating a number of dimensions of the previous concept in 'The Bit Economy'. This paper argues that the bit product, including bit service, are products that exist in cyberspace, using bit as the subject of labor to produce, containing the information content or service, being able to be stored, transferred and used by the information infrastructure and equipment. In addition, we believe that the essence of bit product is that the process of its production, exchanges and uses expresses as 'bit streams'.

As for the Cognition of bit product, we should focus on the following three aspects:

Firstly, existing in cyberspace is the primary characteristics of bit product produced by bit, the only subject of labor in cyberspace. This limitation distinguishes atom product and bit product from the world of existence and indicates the outer limits of the bit product.

Secondly, as other products of labor, bit product also contains undifferentiated human labor, which is embodied in the means of labor used during the production process of bit product contain virtual intellectual means of labor that be represented by human knowledge and based on human intellectual work directly or indirectly.

Thirdly, we must perceive cyberspace through the material interface, so bit product, which must rely on the physical carrier or network to exist, is non-independent. If there are no external material structure, bit product, the valuable information, will not be perceived with its intangible feature. Only when the both are together, they will bring users the utility and value. Interface side is the Newtonian's material world, while the other side is a virtual cyberspace [22]. In virtual cyberspace, people cannot make virtual practice separately, and they must use material interface for the media to do it. The main part of virtual practice is human, while its object is bit product rather than the material things. In recent 
years, mobile phones, panel computers and other high-tech products which are popular among people have developed rapidly. In the final analysis, the strong demand on the bit product is the driving force behind.

\section{Summary}

Following the irresistible trend of the information society, human society is bound to change dramatically. As an important part of the information society research, bit economy is just in its infancy. There are many sub-areas for indepth discussion and research. Clearing the connotation and denotation of bit, cyberspace, and bit product can lay a solid foundation for these studies to promote the bit economy research and even promote research on the whole information society.

\section{References}

[1] Zhong, Yixin (2002), Principles of Information Science. Beijing: BUPT Press.

[2] Shu, Huaying (2012), The Bit Economy. Beijing: The Commercial Press.

[3] Shannon,C. E. (1948), "A Mathematical Theory of Communication," The Bell System Technical Journal, 27(July, October), 379-423, 623-656.

[4] Popper, Karl R. (1972), Objective Knowledge: An Evolutionary Approach. Oxford: Oxford University Press.

[5] Fan, Chunping (2011), "Info-Demon and Information order in a Digitalized World," Studies in Dialectics of Nature, 27(9), 82-87.

[6] Sun, Mutian (2000), "On World 4," Journal of Dialectics of Nature, 22(2), 88-91.

[7] Zhang, Zhicang (2001), "From World 1 to World 4," Studies in Dialectics of Nature, 17(10), 66-70.

[8] Liu, Kesu, and Liang, Qihua (2007), "On the Paradox of World 4: from A Logical Point of View," Studies in Dialectics of Nature, 23(4), 13-17.

[9] Liang, Qihua, and Liu, Kesu (2000), "World 4' Paradox: A Perspective of Ontology," Journal of Dialectics of Nature, 28(6), 93-98.

[10] The White House (2009), Cyberspace Policy Review.

[11] Department of Defense (2010), Dictionary of Military and Associated Terms. Washington: Department of Defense.

[12] Negroponte, Nicholas (1995), Being Digital. New York: Alfred A. Knopf, Inc.

[13] Chen, Xue (2007), "Research Review of Digital Products," Journal of Tianzhong, 22(2), 69-71.

[14] Yi, Li (2005), The Immateriality of Digital Product and Its Design. Changsha: Hunan University.

[15] Yao, Xingen (2004), Research On Digital Mode and Personal Information Appliance Development. Wuxi: Jiangnan University.

[16] Hui, Kai Lung, and Chau, Patrick YK (2002), "Classifying digital products," Communications of the ACM, 45(6), 73-79.

[17] Shapiro, Carl, and Varian, Hal R. (1998), Information Rules : A Strategic Guide to the Network Economy. Boston: Harvard Business School Press.

[18] Rui, Tingxian (2002), The Economics of Electronic Commerce. Beijing: Publishing House of Electronics Industry.

[19] Carl Shapiro, Hal R. Varian (1998), Information Rules: A Strategic Guide to the Network Economy. Boston: Harvard Business Review Press.

[20] Yuan, Hong, Chen, Weizhe (2007), "On the Application of the Particularity of Digital Products Cost Structure," Journal of Information, 26(10), 123-125.

[21] Xie, Kang, Xiao, Jinghua (2003), The Economics of Electronic Commerce. Beijing: Publishing House of Electronics Industry.

[22] Zhou, Changqing (2010), "Discrimination between Digitized Products and Digital Products," CO-Operative Economy \& Science, 24, 122-123

[23] UN, EC, IMF, OECD, UNCTD, and WTO (2002), Manual on Statistics of International Trade in Services. New York: United Nations.

[24] Bao, Yixi, and Yan Sanjiu (2012), "The Visual Construction and Cultural Characterization of Digital Products," Journal of Shanxi University (Philosophy and Social Science Edition), 2, 111-116. 